\title{
Tandem Metal Inert Gas process for high productivity Wire Arc Additive Manufacturing in stainless steel
}

Filomeno Martina ${ }^{1}$, Jialuo Ding ${ }^{1}$, Stewart Williams ${ }^{1}$, Armando Caballero ${ }^{1}$, Gonçalo Pardal ${ }^{1}$, Luisa Quintino $^{2}$

${ }^{1}$ Welding Engineering and Laser Processing Centre, Cranfield University, Cranfield, Bedfordshire MK43 0AL, United Kingdom

${ }^{2}$ IDMEC, Instituto Superior Técnico, Universidade de Lisboa, Av. Rovisco Pais, 1049-001

Lisboa, Portugal, email: lquintino@tecnico.ulisboa.pt

\begin{abstract}
$\underline{\text { Abstract }}$
This study investigates the feasibility of achieving high deposition rate using wire + arc additive manufacturing in stainless steel to reduce lead time and cost of manufacturing. The pulse MIG welding technique with a tandem torch was used for depositing martensitic stainless steel 17-4 $\mathrm{PH}$. The mechanical and metallurgical properties of the manufactured component were analysed to evaluate the limitations and the extent to which the rate of deposition reaches a maximum without any failure or defect being evident in the manufactured component. Deposition rate of $9.5 \mathrm{~kg} / \mathrm{hr}$ was achieved. The hardness was matched for the as deposited condition.
\end{abstract}

Keywords: Wire+arc additive manufacturing, martensitic stainless steel, high deposition rate

\section{Introduction}

Metal Additive Manufacturing (MAM) includes the techniques of depositing metal layer by layer to achieve a given geometry, using heat sources similar to fusion welding. As such laser, electron beam and electric arc are characteristic of the variants of MAM.

Each process associated with MAM technology has its own specific characteristics. Selective laser melting can produce nearly net shape components, electron beam melting process is more appropriate for parts of very small size having very high complexity of design while wire and arc additive manufacturing (WAAM) targets large size metal parts.

The demand to increase the productivity and reduce the lead time and manufacturing cost using the WAAM technique have been challenged by the mechanical and metallurgical properties such as tensile strength, hardness, heat input, microstructure properties and defects in the parts produced.

High productivity welding has been widely studied and the use of tandem torch arrangement has shown benefits when the interaction between the two arcs and the behavior of the weld pool were mastered $[1,2]$. In WAAM the use of tandem torch arrangements presents different challenges as there is no base material and thus no heat affected zone, and no rapid cooling of the deposited material [3].

Previous studies on WAAM of stainless steel report the use of Gas Tungsten Arc Welding (TIG) for 308LSi steel, Cold Metal Transfer (CMT) for 240 steel [4], CMT and automated TIG welding (Top TIG) for stainless steel with the aim of optimizing deposition rate [5] and deposition strategies for any material [6]. An attempt to reach high productivity has been reported by Yuehai Feng [7] using double wire plasma arc in comparison with single wire with good results 
Queguineur, A. et al analyse the potential of additive manufacturing for large components using the CMT process and the consequences on the manufacturing time for austenitic stainless steel parts used in naval construction [8].

In general the studies done to date point out preferential areas of application of the different welding processes that can be used for WAAM. TIG (DC and pulsed) will generate high quality parts with good surface finish, Pulsed MIG is possibly the simplest and most cost effective technique, Cold Metal Transfer (CMT) will allow to deposit layers with low heat input, high process tolerance, plasma and high power fiber laser are adequate for small high quality parts while for achieving the highest productivity Tandem MIG is the most promising technique.

Low alloy steels have gained more relevance in the studies published till now, in particular due to the more significant interest of leader industrial sectors as oil \& gas, energy, defense, automotive and aerospace. High alloy steel studies are less referred [7, 9] in the literature.

The studies of WAAM in steel at present concentrate on searching deposition strategies to obtain parts with no defects or distortion, whilst assuring metallurgical characteristics and mechanical behavior similar to the ones produced with alternative subtracting manufacturing techniques.

17-4 PH stainless steel is a precipitate hardened lath martensitic steel widely used in various industries like aerospace, nuclear plant and oil and gas due to the high strength, high toughness and corrosion resistance [10] obtained due to the uniform distribution of fine intermetallic phases or alloying elements such as niobium and copper.

This hardened steel undergoes phase changes similar to low alloy steels which generate weldability problems usually not associated with stainless steels [9, 11, 12]. By using the Schaeffler Diagram, and calculating $\mathrm{Cr}$ and $\mathrm{Ni}$ equivalent, which are respectively 16.3 and 5.6, martensitic ferritic structure is obtained. This requires the analysis of the weldability problems of both steel grades.

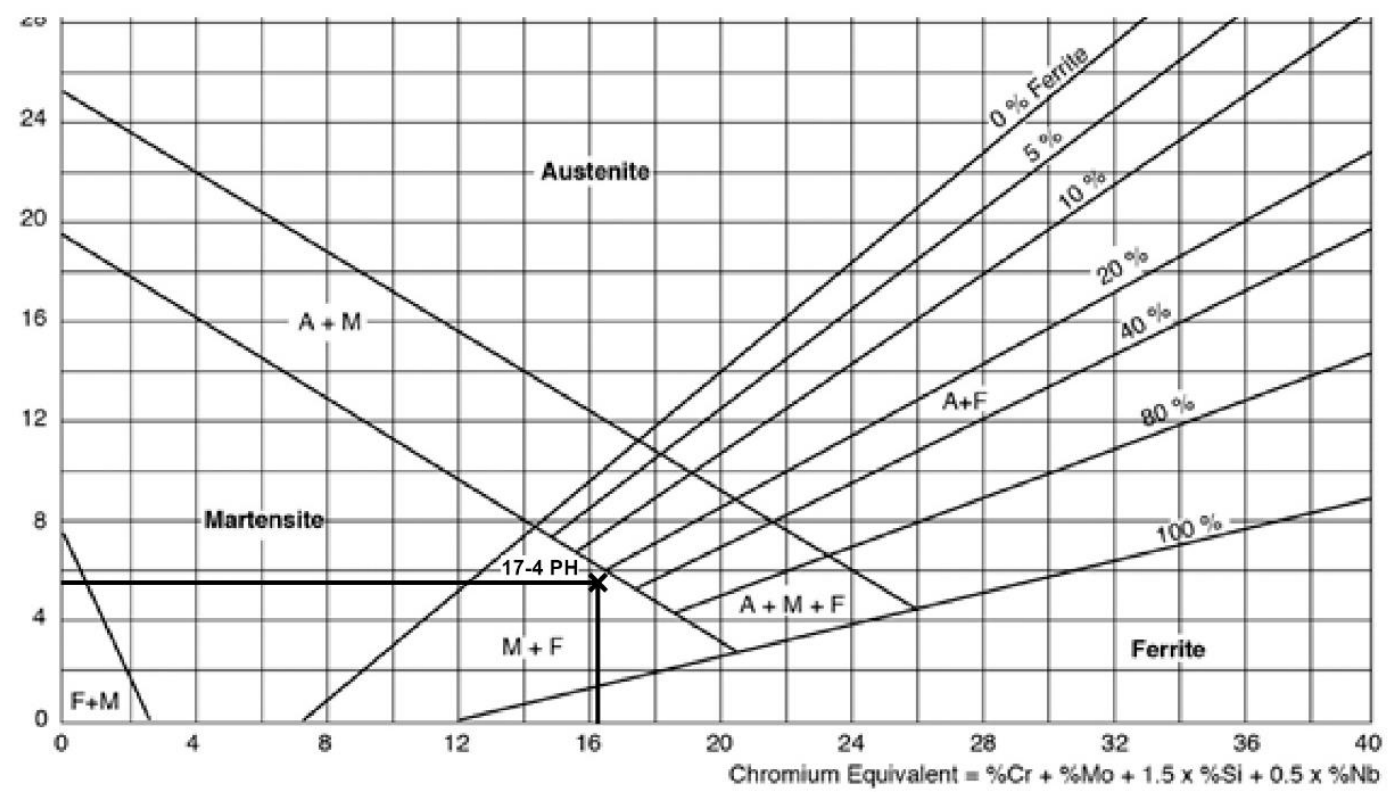

Fig 1. Schaeffler Diagram - 17-4 PH steel

Ferritic stainless steels are difficult to weld due to loss of ductility and toughness associated with grain growth and intercristalline corrosion. Both problems can be minimized by using a welding procedure leading to high cooling rates and thus low heat input. The use of heat input below 1 
$\mathrm{kJ} / \mathrm{min}$ [13] is advised though for the high deposition rate targeted in the present study much higher heat inputs are needed. The martensitic grades are used in more challenging environments and present other weldability problems related with weld cracking, in particular hydrogeninduced cracking. To prevent this, pre-heat and post-weld heat-treatment immediately after welding are viable options to obtain a more ductile structure, less prone to cracking. Minimizing the weldability problems of these grades of steel requires opposite strategies, since for ferritic steels it is advised to use high cooling rates while for martensitic steels low cooling rates are required.

The transformations occurring in the fusion zone of a weld may be similar to WAAM depositions but most of the works published on the weldability of 17-4 PH steel focus on the alterations of microstructure and mechanical properties in comparison with the base material. Only a few investigations relate to the influence of the weld microstructure on the properties of the weld[11, $12]$.

Selective laser melting has been used for production of parts in 17-4 PH steel which report that building orientation has a direct effect on the mechanical properties as vertically built samples exhibit lower yield and tensile strengths and elongation to failure [14] and on fatigue behavior owing to the relative orientation of deposited layers with respect to applied load [15].

The 17-4 PH is a precipitation hardened steel that undergoes two stages of heat treatment. Solution treatment in which it is subjected to both high and low temperature to solubilize the alloy element present and to avoid high growth in the grain size. The aging phenomena can promote the strength but can reduce the toughness of the material [10]. The 17-4 PH stainless steel is a martensitic stainless steel which contains around $3 \% \mathrm{Cu}$ and it gains its strength by the precipitation of highly dispersed copper particles in the martensitic matrix. The solution treatment and cooling of material to room temperature results in a martensitic structure but it yet lacks the high hardness. Aging the 17-4 PH results in precipitation hardening due to the formation of a rich copper precipitates [10].

The use of a double wire to achieve higher deposition rate WAAM was reported in [7], where one and two wires were fed into a plasma-based WAAM setup, for austenitic ferritic stainless steel. The authors concluded that the deposition rate increased by 1.06 times with double wire on an average compared with the single wire process, despite using the same process parameters.

The aim of this study is to investigate the influence of different techniques for deposition of material using WAAM tandem torch process to achieve high deposition rate of 17-4 PH stainless steel. Microstructure and hardness analysis have been analyzed for different heat inputs.

The results will demonstrate that Tandem MIG technology can be successfully adopted for high deposition rate AM of martensitic stainless steel parts, reaching $9.5 \mathrm{~kg} / \mathrm{h}$ with no defects and hardness values similar to the parent material.

\section{Materials and Methods}

\subsection{Materials}

The WAAM technique was used to build linear deposits using 17-4 PH stainless steel with chemical composition shown in Table 1 . Stainless steel plates were used as a substrate material.

Table I - Chemical composition of SS 17-4 PH in weight \% [16] 


\begin{tabular}{|c|c|c|c|c|c|c|c|c|}
\hline $\mathbf{C}$ & $\mathbf{S i}$ & $\mathbf{M n}$ & $\mathbf{C r}$ & $\mathbf{C u}$ & $\mathbf{N i}$ & $\mathbf{N i}+\mathbf{T a}$ & $\mathbf{P}$ & $\mathbf{S}$ \\
\hline 0.033 & 0.40 & 0.49 & 15.57 & 3.31 & 4.37 & 0.23 & 0.027 & 0.001 \\
\hline
\end{tabular}

In this present study the emphasis was laid upon building walls to analyze variable deposition rate and followed by mechanical and metallurgical tests to compare with parent material. A pulse MIG welding technique was employed using tandem troch which can facilitate dual wire deposition simultaneously and as such achieve high productivity.

\subsection{Experimental Setup}

The setup uses a tandem torch, two synchronized power sources, chiller plate, substrate plate, shielding gas, KUKA robot, computer and jigs as shown in Figure 2. The tandem torch is connected to a six-axis KUKA robot. The torch angle used was $84^{\circ}$ and the welding parameters were set to give a layer height of $1,6 \mathrm{~mm}$. The power source is used to initiate the welding process which works in tandem with the robot. The deposition of material is done on a stainless steel substrate plate and a chiller plate is placed under it for cooling purpose. Shielding gas, which is used to control the environment around the arc, is connected to the tandem torch. The gas flow rate used was $27 \mathrm{l} / \mathrm{mn}$

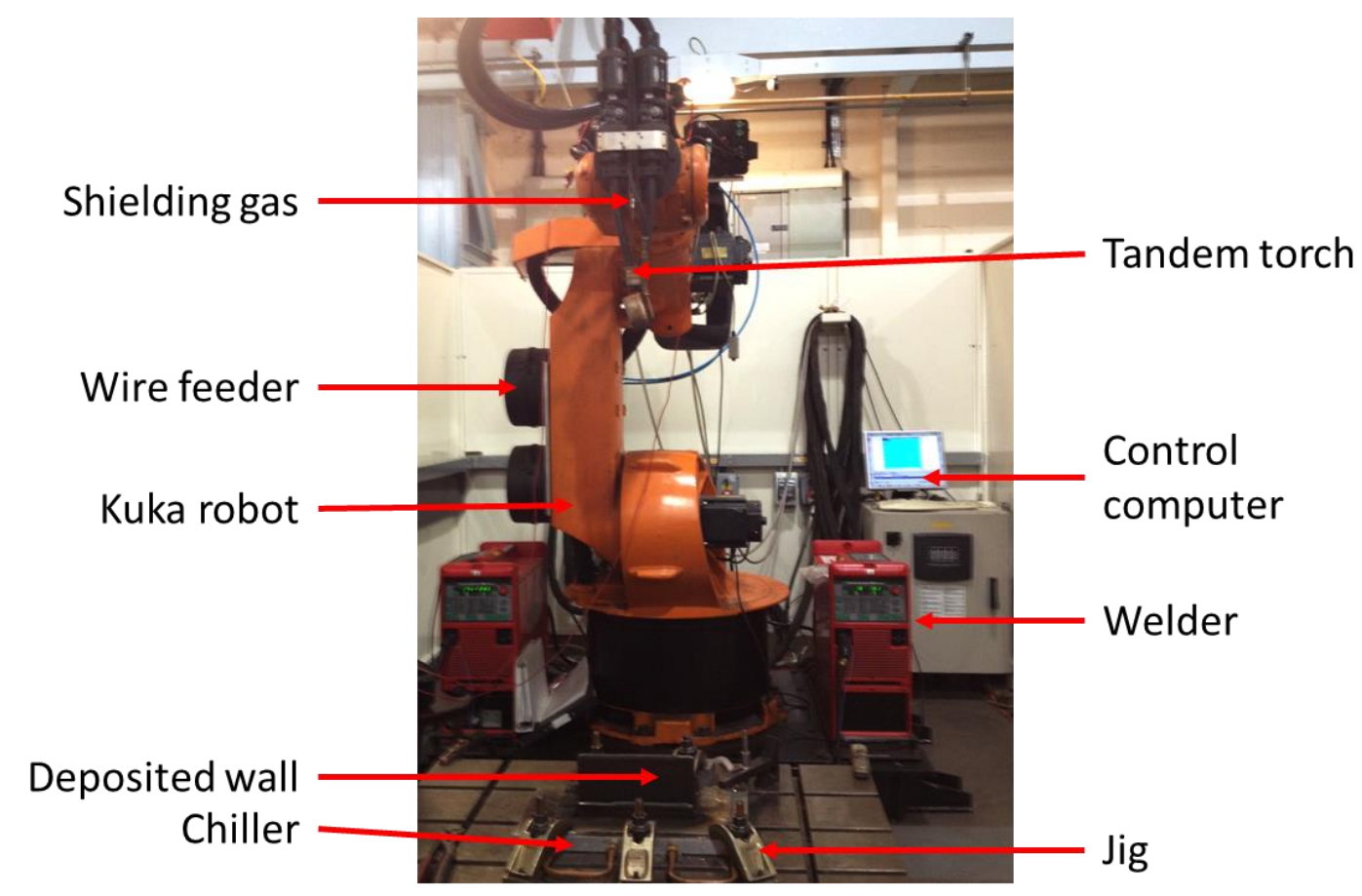

Fig. 2. Pulse MIG welding tandem torch experimental setup

The contact-to-workpiece distance is a very critical factor in this type of process, as any marginal error can cause the increase or decrease in droplet size and also in the size of the arc. Therefore this parameter was carefully controlled by measuring after the deposition of each layer. Figure 3 shows the tandem torch in lead-and-trail mode, as well as a close-up of the starting plate while clamped. 


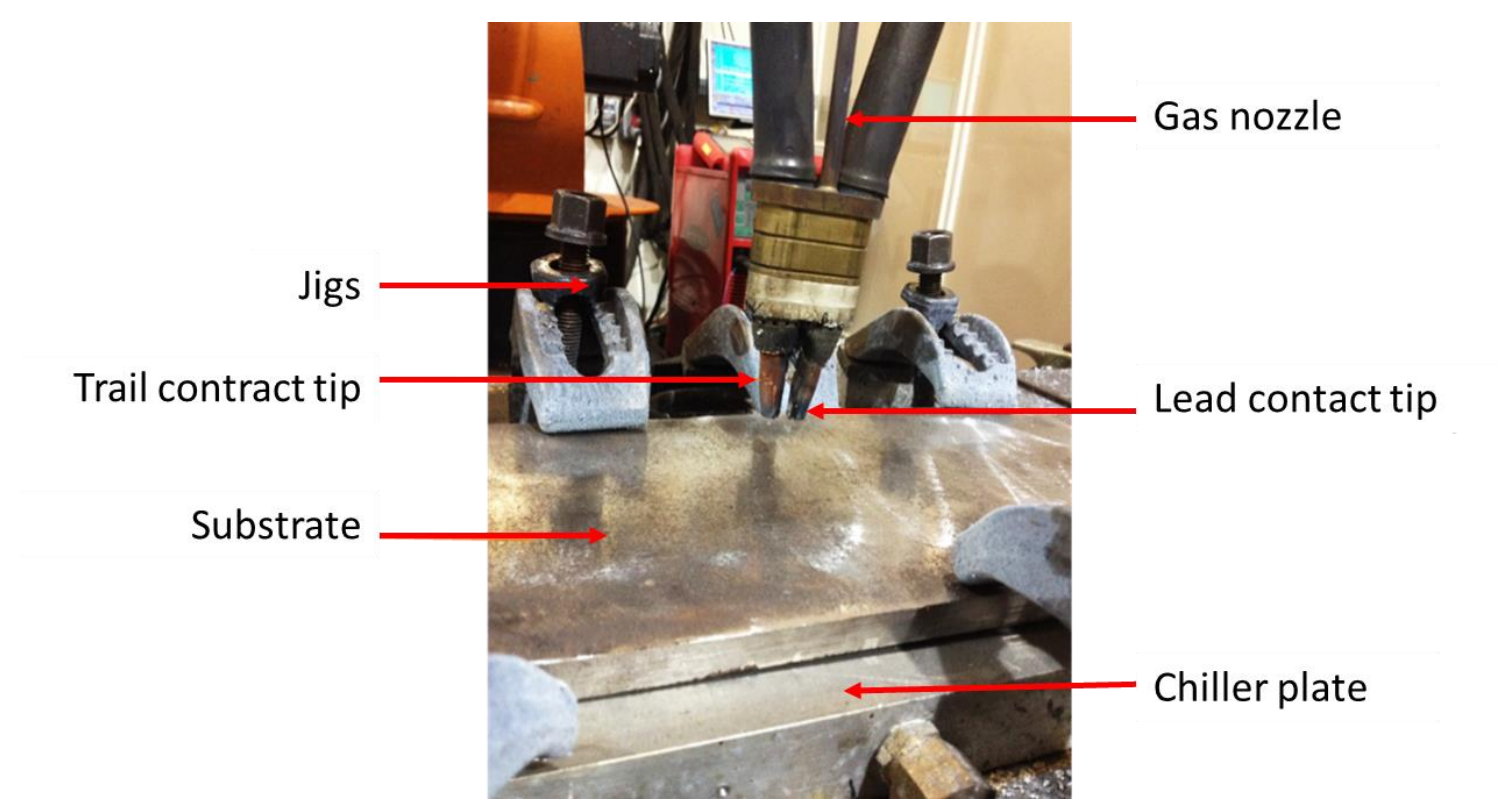

Fig. 3. Tandem torch working configuration

\subsection{Experimental Plan}

A filler wire with a diameter of $1.2 \mathrm{~mm}$ diameter was used under a shielding gas with $2.5 \% \mathrm{CO}_{2}$ in Argon. The contact tip to work distance was kept constant at $20 \mathrm{~mm}$ by measuring after each layer. The constant parameters were the gas flow rate which was kept constant at $25 \mathrm{l} / \mathrm{min}$ and the layer height which was kept constant at $1.6 \mathrm{~mm}$. The torch angle was set at 84 degree and the gas flow pressure was maintained at a constant pressure of $4 \mathrm{MPa}$. The variable parameters were wire feed speed (WFS) with a range of 7.5 to $10.5 \mathrm{~m} / \mathrm{min}$ and travel speed (TS) with a range of 1 to $1.5 \mathrm{~m} / \mathrm{min}$.

The following strategy was followed:

1. Identification of basic set of working process parameter, wire feed speed (WFS) and travel speed (TS).

2. Deposited wall analysis was carried out to determine the wall shape dimensions and to check for any discontinuity. The walls were built at a variable WFS and TS.

3. Parameters were further altered to develop walls using different deposition techniques, single pass and oscilation.

4. Microstructural analysis was carried out using optical microscope to analyse the size and distribution of the grains and also phase transformation.

5. Hardness test was carried out on horizontal and vertical cross section

In order to view the microstructure in different planes and how the heat flow was affecting the development of the grains, phase transformation and the microstructure, two samples were cut from the center of each deposit, and then further cut into horizontal and vertical cross-sections. The horizontal one was cut in $20 \mathrm{~mm} \times 20 \mathrm{~mm}$ size, whereas the vertical one was cut into $10 \mathrm{~mm} \mathrm{x}$ $20 \mathrm{~mm}$ size.

Vickers hardness measurements were taken on both the vertical and horizontal sections of the samples. The hardness identifications 6 in the $\mathrm{V}$ direction and 6 in the $\mathrm{H}$ direction were positioned to cover the overlap zones between layers. 
After achieving the best deposition rate with lead and trail technique, an oscillation deposition strategy was adopted to assess the possibility of depositing large widths at high deposition rates by constructing an oscillated wall of dimension of $210 \mathrm{~mm}$ in length, $40 \mathrm{~mm}$ in height, width of $50 \mathrm{~mm}$ and step advancement of $6.6 \mathrm{~mm}$.

\section{Results and discussion}

\subsection{Effect of WFS and TS on Deposition rate}

The trials for deposition were conducted at different ranges of WFS and TS as shown in Figure 4. Weld failure was assessed through visual inspection for identifying superficial porosity excessive melting, discontinuities and collapsing. Failure can be attributed either to

- The fact that a high amount of material is being deposited at low TS. In such cases, the TS needs to be increased to achieve a successful weld, or

- The high heat accumulation, with excessive metal being deposited at a slower TS, high current phase and short circuit. As such current was regulated to avoid high current phase and arc length correction was altered between a ranges of 20-30\% to avoid short circuit.

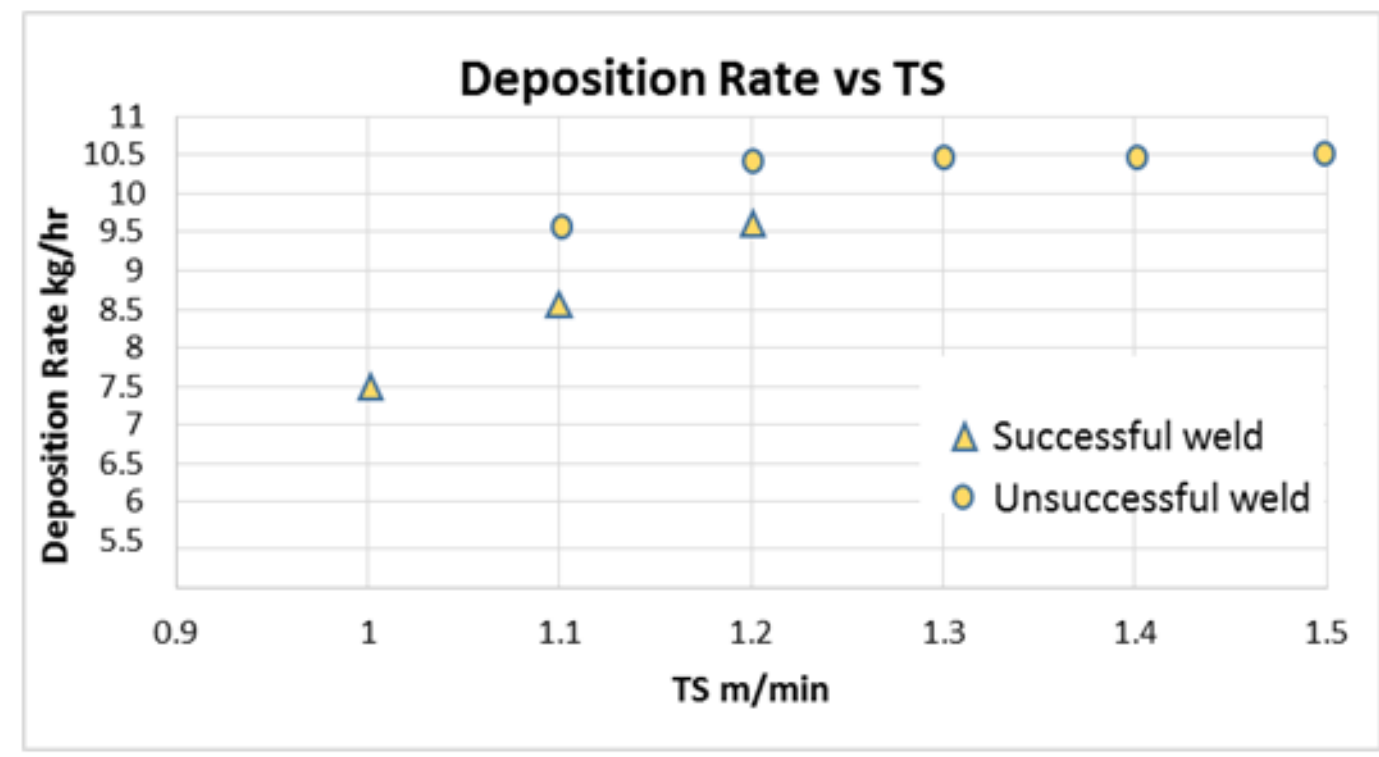

Fig. 4. Weld attempts using two different wire.

Occasional discontinuities were seen in some walls, as shown in Figure 5. These were due to the excessive heat input, which does not enable a good deposition over a hot surface, because the metal in molten state does not stay stable over the pre build layer which remains very hot. Failure was observed in some of the walls due too much of high end current duration. 


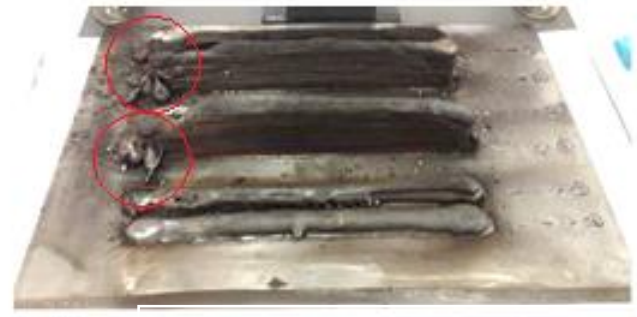

a)

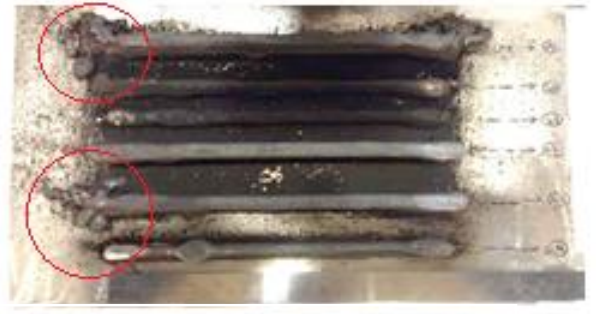

b)

Fig. 5. Wall failures during multiple deposition trials, a) Wall failure due to high heat input (WFS $=10 \mathrm{~m} / \mathrm{min}, \mathrm{TS}=1.2$ to $1.5 \mathrm{~m} / \mathrm{min}$ ); b) Wall failure due to high end current duration $(\geq$ $0,2 \mathrm{~s})$

Once the cause of failure was determined, the welding parameters were changed, with the end current parameter altered to $0.1 \mathrm{~s}$, and the post gas flow was set at $0.2 \mathrm{~s}$. Successful weld were achieved for WFS of 7 and $9 \mathrm{~m} / \mathrm{min}$ and TS of 1 and $1.2 \mathrm{~m} / \mathrm{min}$, as shown in Figure 6 in samples with $210 \mathrm{~mm}$ in length, $40 \mathrm{~mm}$ in height and width of $50 \mathrm{~mm}$.

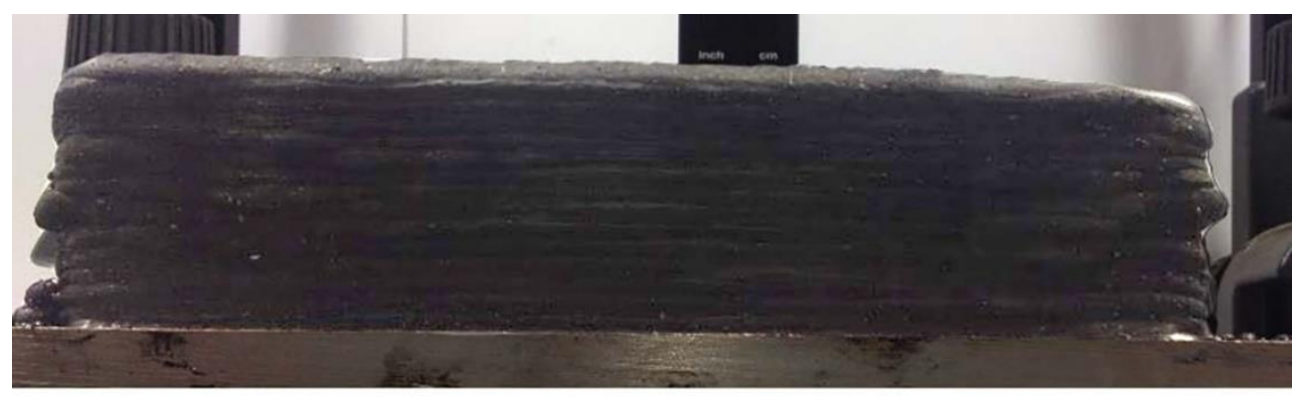

(a) Wall deposited at a WFS of $7 \mathrm{M} / \mathrm{MIN}$

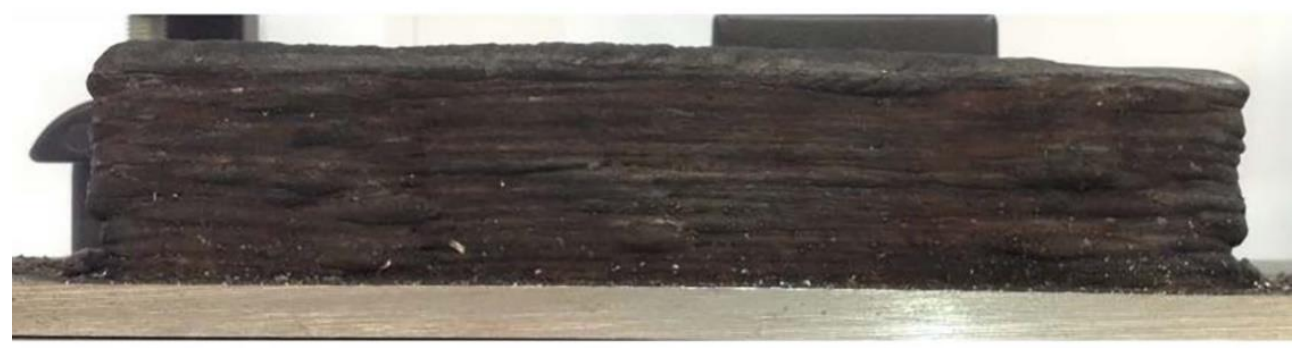

(b) Wall deposited at a WFS of $9 \mathrm{M} / \mathrm{MIN}$

Fig. 6. Successful walls developed during second stage experiment, a) Wall deposited at a WFS of 7 M/MIN; b) Wall deposited at a WFS of 9 M/MIN

The deposition rates, determined from equation 1, using the average WFS, known the diameter and the material's density, are shown in Table II.

Deposition Rate $=$ Density $(\mathrm{kg} / \mathrm{cm} 3) \times$ WFS $(\mathrm{cm} / \mathrm{hr}) \times \pi \times$ Wire Diameter $2 / 4(\mathrm{~cm})$ 
Table II - Deposition rates

\begin{tabular}{|c|c|}
\hline $\begin{array}{c}\text { Deposition } \\
\text { WFS } \\
(\mathrm{m} / \mathrm{min})\end{array}$ & $\begin{array}{c}\text { Deposition rate of second } \\
\text { stage experiment }(\mathrm{kg} / \mathrm{h})\end{array}$ \\
\hline 7 & 7.4 \\
\hline 8 & 8.4 \\
\hline 9 & 9.5 \\
\hline
\end{tabular}

The walls were built at a variable WFS of 7,8 and $9 \mathrm{~m} / \mathrm{min}$. The highest deposition rate of 9.5 $\mathrm{kg} / \mathrm{h}$ was achieved at WFS of $9 \mathrm{~m} / \mathrm{min}$ and TS of $1.2 \mathrm{~m} / \mathrm{min}$, beyond which high discontinuity in deposition was observed as shown in Figure 5 with a WFS of $10 \mathrm{~m} / \mathrm{min}$ and with an altered TS ranging from 1.2 to $1.5 \mathrm{~m} / \mathrm{min}$.

The oscillation technique was used, with the parameters that led to higher deposition rates, to produce walls with high thickness following the path in figure 7. During the process high distortion as shown was observed in the substrate due to the high heat input. During the deposition process it was found that the heat input remains the same during the lead and trail technique but the cooling of the wall during the process was very slow (fig. 8).

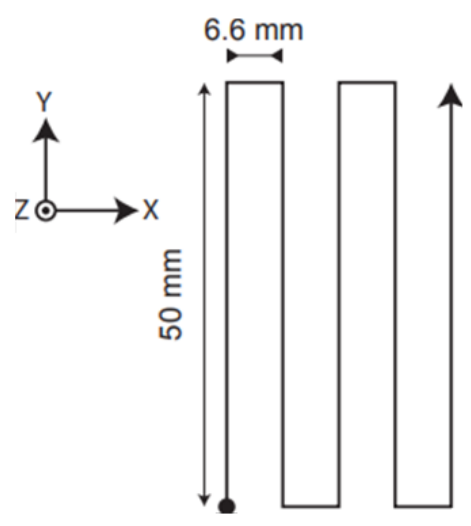

Fig. 7 - Schematic of the oscillation pass

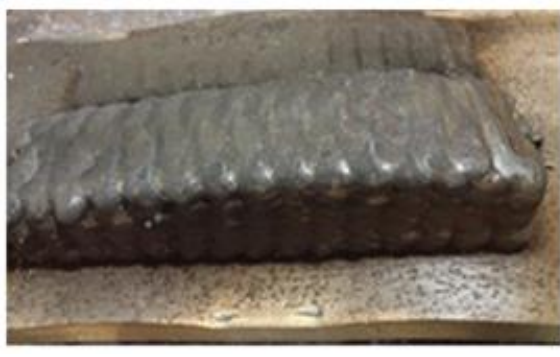

Fig. 8. Distortion during oscillation

\subsection{Microstructure analysis}


The microstructure analysis was made on horizontal and vertical cross-section as referred in item 2 to see how the material behaves under the process conditions and what changes it undergoes. It has been reported that for SLM parts in 17-4 PH post processing heat treatment is advised to achieve a homogeneous microstructure [17]. Since post processing always adds to cost and complexity of the process, the aim is to obtain a WAAM microstructure similar to wrought 17-4 PH steel.

Phase transformation, grain orientation and size as well as the effect of heat and cooling cycle on the material, were analysed. During the observation of the microstructure it was found that the grain orientation was not homogenous and the size of the grains increased gradually with the increase in heat input.

The comparison of the microstructure for two different WFS depicted in Figure 9 showed a slight increase in grain size and columnar grain size with an increase in heat input. This phenomenon occurred due to the increased heat input and lower cooling rate associated with higher WFS.

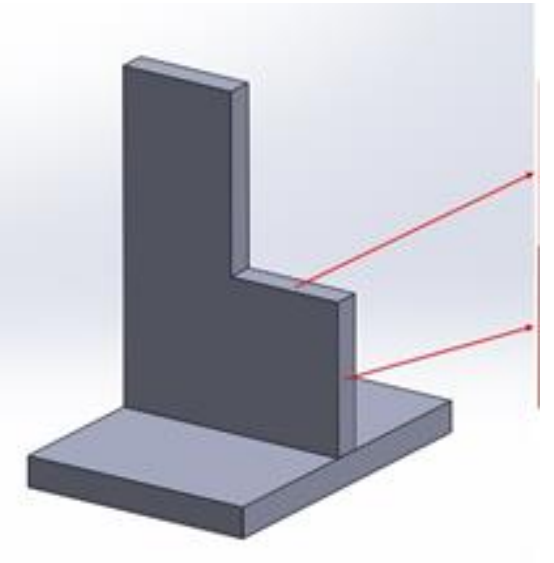

c)

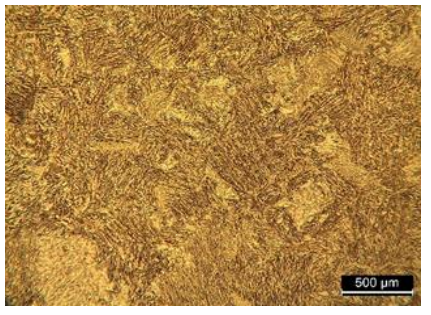

a)

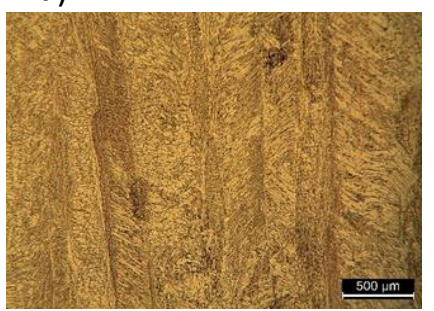

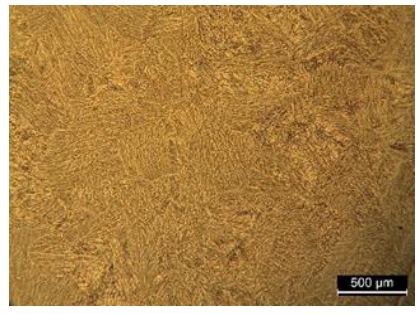

b)

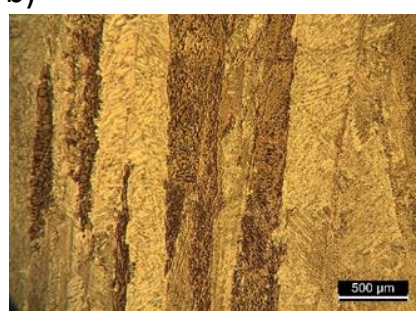

d)

Fig. 9. Microstructure comparison, a) Horizontal phase at WFS $7 \mathrm{~m} / \mathrm{min}$; b) Horizontal phase at WFS $8 \mathrm{~m} / \mathrm{min}$; c) Vertical phase at WFS $7 \mathrm{~m} / \mathrm{min}$; d) Vertical phase at WFS $8 \mathrm{~m} / \mathrm{min}$

As the grain size increases with the increase in WFS the strength and the hardness of the material decreases and this trend can be inferred from the results obtained from the hardness test, as with the increase in the WFS the hardness starts gradually decreasing.

The "as deposited" 17-4 PH WAAM is a dendritic microstructure with the presence of interdendritic $\delta$-ferrite in a lath martensitic matrix. No non-metallic inclusions were observed.

The phase transformation of the material was observed to be completed into a martensitic phase with negligible presence of austenite. The microstructure observation was also made to detect presence of any non-metallic inclusion, which occur in SLM of 17-4 PH [17] or any defect at the grain boundaries which were not found to be present. The microstructure also shows that the grains are undergoing a change from finer to coarser but the effect of high heat input cycle and low cooling rate does not promote the grain growth to a very extreme extent.

\subsection{Hardness Tests}

The hardness tests aim at verifying if there is decrease on the samples in particular when higher WFS and thus deposition rates are achieved. If this happens, as 17-4 PH is a precipitationhardening stainless steel post heat treatment and different hardening processes may be required 
to increase the hardness of the material, but during this process the material has a tendency to lose its toughness.

The hardness tests results on average from 6 points in the $\mathrm{V}$ direction, and 6 in the $\mathrm{H}$ are shown in Table III. According to the T-test samples (the size of each sample for the T-test was 12), and with a significance level of 0.05 , the difference between the specimens built with WFS $=7 \mathrm{~m} / \mathrm{min}$ and WFS $=8 \mathrm{~m} / \mathrm{min}$ is not statistically significant ( $\mathrm{p}$-value $=0.8598$ ). Instead, the difference between the specimens built with WFS $=8 \mathrm{~m} / \mathrm{min}$ and WFS $=9 \mathrm{~m} / \mathrm{min}$ is statistically significant $(\mathrm{p}$-value $=0.0192)$.

Table III - Hardness test results (shielding gas $2.5 \% \mathrm{CO}_{2}$ in Argon)

\begin{tabular}{|c|c|c|}
\hline & \multicolumn{2}{|c|}{ Hardness Vickers } \\
\hline $\begin{array}{c}\text { Wire Feed Speed } \\
(\mathrm{m} / \mathrm{min})\end{array}$ & Average & St. Dev \\
\hline 7 & 348.2 & 10.4 \\
\hline 8 & 347.5 & 7.6 \\
\hline 9 & 340.2 & 6.6 \\
\hline
\end{tabular}

The hardness test results using a tandem troch pulse MIG welding with a lowest deposition rate of $4.5 \mathrm{~kg}$ was seen to be around $398 \mathrm{HV}$ [10]. The results obtained for higher deposition rates are close to the single CMT process from the past study, which at much lower deposition rate achieved a hardness of $340 \mathrm{HV}$. The present values are close the parent material hardness which is sated as $349 \mathrm{HV}$.

\section{Conclusions}

- The highest deposition rate of $9.5 \mathrm{~kg} / \mathrm{h}$ was achieved at wire feed speed of $9 \mathrm{~m} / \mathrm{min}$ and travel speed of $1.2 \mathrm{~m} / \mathrm{min}$.

- Pulse MIG welding technique with a tandem torch was observed to be suitable for the high deposition rate as the dual wire feeding technique increased the deposition by two times with the process being stable at higher deposition rate.

- No significant change in hardness was observed with increase in WFS during the process.

- $9.5 \mathrm{~kg} / \mathrm{h}$ deposition rate was achievable with both lead and trail technique and oscillation technique.

- For production of thick sections, the tandem process at higher WFS may require better external cooling atmosphere, such as a blow of compressed air or cryogenic cooling and these must be examined for this process.

\section{References}

1. D.V. Kiran, D.W. Cho, W.H. Song, S.J. Na, Arc behavior in two wire tandem submerged arc welding, Journal of Materials Processing Technology, 214 (8), pp. 1546-1556 (2014).

2. D.W. Cho, D.V. Kiran, W.H. Song, S.J. Na, Molten pool behavior in the tandem submerged arc welding process, Journal of Materials Processing Technology, 214 (11), pp. 2233-2247 (2014) 
3. S Moeinifar, A.H. Kokabi, H.R.M. Hosseini, Effect of tandem submerged arc welding process and parameters of Gleeble simulator thermal cycles on properties of the intercritically reheated heat affected zone, Materials \& design, 32 (2), pp. 869-876 (2011).

4. O. Yilmaz, A.A. Ugla, Microstructure characterization of SS308LSi components manufactured by GTAW-based additive manufacturing: shaped metal deposition using pulsed current arc, Int. J. Adv. Manuf. Technol., 89, pp. 13-25 (2016).

5. Rodriguez N. et all, Wire and arc additive manufacturing: a comparison between CMT and TopTIG processes applied to stainless steel. Welding in the World, pp1-14 (2018) https://doi.org/10.1007/s40194-018-0606-6, ISSN: 00432288; 18786669

6. Helen Lockett, Jialuo Ding, Stewart Williams \& Filomeno Martina, Design for Wire + Arc Additive Manufacture: design rules and build orientation selection, Journal of Engineering Design, vol. 28, pp. 568-598, ISSN: 0954-4828 (Print) 1466-1837 (Online) DOI: $10.1080 / 09544828.2017 .1365826$

7. Yuehai Feng, Bin Zhan, Jie He, Kehong Wang, The double-wire feed and plasma arc additive manufacturing process for deposition in Cr-Ni stainless steel, Journal of Materials Processing Tech., 259, pp. 206-215, (2018) https://doi.org/10.1016/j.jmatprotec.2018.04.040

8. Queguineur, A., Ruckert, G., Cortial, F., Hascoet, J. Y.), Evaluation of wire arc additive manufacturing for large-sized components in naval applications, Welding in the World, 62, pp. 259-266, 2018, DOI: 10.1007/s40194-017-0536-8

9. Jinguo $\mathrm{Ge}$, Jian Lin, Yongping Lei, Hanguang $\mathrm{Fu}$, Location-related thermal history, microstructure, and mechanical properties of arc additively manufactured $2 \mathrm{Cr} 13$ steel using cold metal transfer welding, Materials Science \& Engineering A, DOI:10.1016/j.msea.2017.12.076

10. Tavares, S S.M., Corte, S.Joaquim, Pardal, Juan M., Failure of 17-4 PH stainless steel components in offshore platforms. Book Chapter of Handbook of Materials Failure Analysis with Case Studies from the Oil and Gas Industry (2016), DOI:10.1016/B978-008-100117-2.00019-4

11. A. Ziewiec, E. Tasak, J. Czech, Cracking of welded joints of the 17-4PH stainless martensitic steel precipitation hardened with copper, Archives of Metallurgy and Materials, 50, 3, 1055-1061 (2012).

12. A. Ziewiec, A. Zielinska-Lipiec, E.Tasak, Microstructure of Welded Joints of X5CrNiCuNb16-4 (17-4 PH) Martensitic Stainless Steel After Heat Treatment, Archives of metallurgy and materials, Volume 59, Issue 3 (2014) DOI: 10.2478/amm-2014-0162

13. Job Knowledge TWI Mathers G. "Welding of ferritic/ martensitic stainless steels, Twiglobal.com

14. M. Mahmoudi, A. Elwany, A. Yadollahi, S.M.Thompson, L.K. Bian, N. Shamsaei, Mechanical properties and microstructural characterization of selective laser melted 174 PH stainless steel, Rapid Prototype. J., 23 (2), pp. 280-294, (2017). 
15. A. Yadollahi, N. Shamsaei, S.M. Thompson, A.Elwany, L. Bian, Effects of building orientation and heat treatment on fatigue behavior of selective laser melted 17-4 PH stainless steel, Int. J. Fatig., 94, pp. 218-235, 2017.

16. Schönbauer, B.M., Yanase, K. and Endo, M., VHCF properties and fatigue limit prediction of precipitation hardened 17-4PH stainless steel, International Journal of Fatigue, 88, pp. 205-216 (2016).

17. Sudha Cheruvathur, Eric A. Lass, Carelyn E. Campbell, Additive Manufacturing of 174 PH Stainless Steel: Post-processing Heat Treatment to Achieve Uniform Reproducible Microstructure, JOM, Vol. 68, No. 3, 2016, DOI: 10.1007/s11837-015-1754-4.

18. Sun, Yu, Hebert, Rainer J., Aindow, Mark, Non-metallic inclusions in 17-4PH stainless steel parts produced by selective laser melting, Materials \& Design, vol. 140, pp. 153162, 2018, DOI: 10.1016/j.matdes.2017.11.063 
2018-11-19

Tandem Metal Inert Gas process for high productivity Wire Arc Additive Manufacturing in stainless steel

\author{
Martina, Filomeno
}

Elsevier

Martina F, Ding J, Williams S, et al., (2019) Tandem Metal Inert Gas process for high productivity Wire Arc Additive Manufacturing in stainless steel. Additive Manufacturing, Volume 25, January 2019, pp. 545-550

https://doi.org/10.1016/j.addma.2018.11.022

Downloaded from Cranfield Library Services E-Repository 